\title{
Aula de Trabalho Pedagógico Coletivo (ATPC) na escola PÚbliCA No ESTAdo de SÃo PAUlo: BREVES CONSIDERAÇõeS CRÍTICAS
}

\author{
COLLECTIVE PEDAGOGICAL WORK CLASS (ATPC) IN PUBLIC SCHOOL IN THE \\ STATE OF SÃo PAULO: BRIEF CRITICAL CONSIDERATIONS
}

\author{
Jorge Luis Sansigolo Ribeiro \\ Mestrando em Educação, Universidade Nove de Julho - UNINOVE \\ São Paulo, SP - Brasil \\ jorge.ribeiro01@educacao.sp.gov.br
}

\author{
Viviane Oliveira da Silva \\ Mestranda em Educação, Universidade Nove de Julho - UNINOVE \\ São Paulo, SP - Brasil \\ vivianemarcos2003@gmail.com
}

Celso do Prado Feraz de Carvalho Doutor em Educação, Pontifícia Universidade Católica de São Paulo - PUCSP São Paulo, SP - Brasil cpfcarvalho@gmail.com

\begin{abstract}
Resumo: O debate acerca dos processos de formação continuada é objeto de políticas educacionais e extensa produção bibliográfica há um tempo considerável, revelando não somente sua importância, como seus problemas. No Estado de São Paulo, no contexto das políticas de formação continuada da SEE/SP, foi criada a Atividade de Trabalho Pedagógico Coletivo (ATPC), com o objetivo de ser um espaço que permitisse aos professores discutir as questões pedagógicas, seu cotidiano e suas demandas, se apropriando de conhecimentos necessários para a superação de problemas. $\mathrm{O}$ artigo apresenta uma breve trajetória dos processos de regulação da ATPC no Estado de São Paulo, analisa as intenções da formação continuada expressas na legislação e aponta seus problemas. Reforça, em sua conclusão, a necessidade de repensar a ATPC como política de formação isolada, pois a forma como a carreira docente é fragmentada impede que o professor possa exercer sua atividade em uma única escola.
\end{abstract}

Palavras-chave: Formação continuada. Políticas educacionais. Atividade de trabalho pedagógico coletivo. Professores. Estado de São Paulo.

Abstract: The debate about continuing education processes is the subject of educational policies and extensive bibliographic production, revealing not only its importance, but also its problems. In the State of São Paulo, in the context of the continuing education policies of SEE / SP (State Education Secretariat of São Paulo), the Collective Pedagogical Work Activity (ATPC) was created in order to create a space that would allow teachers to discuss pedagogical issues, their daily lives and problems, acquiring the necessary knowledge to overcome these problems. The article presents a brief trajectory of the ATPC regulation processes in the State of São Paulo, analyzes the intentions of continuing education expressed in the legislation and points out its problems. It concludes by reinforcing the need to rethink ATPC as an isolated training policy, since the way in which the teaching career is fragmented, prevents the teacher from exercising his activity in a single school.

Keywords: Continuing education. Educational policies. Collective pedagogical work activity. Teachers. State of São Paulo.

Para citar - ABNT NBR 6023:2018

RIBEIRO, Jorge Luis Sansigolo; SILVA, Viviane Oliveira da; CARVALHO, Celso do Prado Feraz de. Aula de Trabalho Pedagógico Coletivo (ATPC) na escola pública no estado de São Paulo: breves considerações críticas. Cadernos de Pós-graduação, São Paulo, v. 19, n. 2, p. 60-69, jul./dez. 2020. Disponível em: https://doi.org/10.5585/cpg.v19n2.18171. 


\section{Introdução}

A formação de professores continua a ser um dos temas mais presentes no debate educacional, nas publicações especializadas e nas políticas educacionais públicas. Embora a discussão e o debate sobre sejam importantes, a permanência constante na agenda das questões que envolvem a formação dos professores, revela ser uma situação que apresenta problemas, inquietações e desconforto. Exemplo recente desse desconforto é o intenso processo recente de normatização pelo qual passa a formação de professores. Nesse contexto, em um curto período de tempo, cerca de quatro anos, o Conselho Nacional de Educação aprovou duas resoluções estabelecendo as regras gerais de organização da formação inicial de professores para a educação básica: a Resolução $\mathrm{CNE} / \mathrm{CP}$ n $^{\circ}$ 2, DE $1^{\circ}$ de julho DE 2015 e a Resolução CNE/CP nº 2, de 20 de dezembro de 2019.

Com o que diz respeito ao debate para sanar as questões e os problemas que a formação de professores incita, uma das estratégias de ação tem sido tentar melhorar a formação do professor em serviço. Nesse sentido, um conjunto de ações foram encaminhadas nos últimos anos, especificamente no sentido de oferecer aos professores formação continuada. Assim, tal formação continuada tem sido uma das ações mais comuns, e tem assumido as formas mais diferenciadas ao longo do tempo

No mesmo contexto e processo em que se deu a discussão sobre a formação continuada de professores, surgiram, também, as preocupações com a gestão democrática da escola. Assim, essas duas preocupações, tornaram-se questões importantes no debate entre os professores, especificamente no contexto da democratização do país, na década de 1980.

Uma das ações efetivadas para dar conta dessas duas questões foi a formulação de políticas para as escolas públicas, que passaram a ter horários específicos para que os professores pudessem problematizar questões importantes para o cotidiano escolar. No Estado de São Paulo, em 1996, a Secretaria de Educação, por meio da portaria n ${ }^{\circ} 1 / 96$, da Coordenadoria de Estudos e Normas Pedagógicas, criou, para as escolas da rede estadual de ensino, o Horário de Trabalho Pedagógico Coletivo (HTCP). A portaria destacava como objetivo:

\footnotetext{
Articular os diversos segmentos da escola para construção e implementação do seu trabalho pedagógico. Fortalecer a Unidade Escolar como instância privilegiada do aperfeiçoamento do seu Projeto Pedagógico. (Re) planejar e avaliar as atividades de sala de aula, tendo em vista as diretrizes comuns que a escola pretende imprimir ao processo de ensino aprendizagem. (SÃO PAULO/ CENP, 1996)
}

A intenção com essa política era abrir espaço, durante o horário de trabalho do professor, para aprimorar sua formação, ou seja, transformar esses horários em momentos de formação continuada. Ao mesmo tempo, visava dar materialidade às questões da gestão democrática nas escolas. 
O discurso oficial definiu o HTPC como uma oportunidade para as unidades escolares da rede estadual de ensino, a partir de uma perspectiva de gestão democrático-participativa, contribuir no planejamento coletivo das decisões educacionais.

Em sua origem, o HTPC foi configurado para ser um espaço organizado para a formação continuada, que visava contribuir com o desenvolvimento da autonomia docente, e para o trabalho conjunto entre os profissionais da educação. Nesse sentido, uma das suas preocupações do HTPC era ampliar o debate sobre gestão democrática, além de criar condições para a abertura da escola à discussão com a comunidade interna e externa, sob uma perspectiva democrática.

Considerando o panorama supracitado, este artigo apresenta inicialmente uma breve caracterização do processo de implementação da ATPC nas escolas da rede estadual de ensino. Após isso, apresenta uma breve revisão bibliográfica, problematizando as contribuições e críticas à ATPC, tendo como objetivo apresentar uma breve trajetória dos processos de regulação da ATPC no Estado de São Paulo, e analisar as intenções da formação continuada expressas na legislação, apontando seus problemas.

Breve itinerário da implantação da ATPC nas escolas da rede estadual de ensino de São Paulo

O contexto político brasileiro da década de 1980 foi marcado pelo processo de democratização do país, que contou com a participação de inúmeras organizações da sociedade civil, entre elas os sindicatos de professores. Como resultado desse processo político, tivemos não somente a derrota da Ditadura Civil-militar que foi implantada em 1964, como a reorganização do processo político, a elaboração de uma nova Constituição, a fundação de partidos políticos, entre outras ações importantes dentro da conjuntura do país. É válido ressaltar que, entre as organizações atuantes nesse processo, as vinculadas ao magistério cumpriram papel de destaque.

As greves de trabalhadores da educação nos fins da década de 1970 e por toda a década de 1980, foram momentos importantes no enfrentamento da Ditadura e na construção do processo e democratização. Nas tarefas cotidianas da luta política, as críticas não se concentravam apenas no autoritarismo político vigente no Estado. Ao invés disso, o questionamento dos processos internos de organização da escola, dos processos de tomada de decisões, das condições de trabalho dos docentes e das condições de formação também foram incorporadas na agenda. Assim, o enfrentamento do autoritarismo estatal implicava, simultaneamente, no enfrentamento do autoritarismo vigente também nas instituições escolares.

No contexto das reivindicações docentes às condições de trabalho, salário e carreira, foram incorporadas agendas pela democratização da escola, estas demonstrando certa preocupação com 
a formação dos professores. Dessa forma, no Estado de São Paulo, desde a década de 1980, a discussão acerca da democratização da escola e da formação dos professores estiveram presentes na agenda da Associação dos Professores do Ensino Oficial do Estado de São Paulo (APEOESP). Por meio da ação política do sindicado dos professores, abriu-se, então, uma frente de luta em que uma das reivindicações era

(...) uma jornada de trabalho que contemplasse um tempo de discussão coletiva no interior da escola, a fim de que pudessem discutir sobre os problemas educacionais, as demandas de seu trabalho, a realidade escolar e organização de intervenções coletivas. (GEPD, 2020)

Em 1982, foram realizadas eleições gerais no país, exceto para a Presidência da República. Esse processo permitiu a ascensão ao governo do Estado de São Paulo de um conjunto de forças políticas organizadas em torno do Partido do Movimento Democrático Brasileiro (PMDB), o partido que surgiu do antigo Movimento Democrático Brasileiro (MDB), oposição consentida durante os anos da Ditadura. Nesse contexto, foi eleito para governar o Estado, no período 1983-1986, André Franco Montoro.

Com o que diz respeito a este governo, as expectativas em relação a tal eram imensas, inclusive entre os trabalhadores da educação. Entretanto, medidas de caráter emergencial e com pouca possibilidade de lidar com as questões eram anunciadas, como se fossem capazes de resolver os problemas estruturais. Entre essas medidas, a SEE/SP criou as Oficinas Pedagógicas, os Programas Especiais de Ensino, o que previa a utilização de computadores pelas escolas, e estabelecia a Jornada Única para o Ciclo Básico, dando origem ao HTP - Hora de Trabalho Pedagógico. (PALMA FILHO, 2004, p. 7)

Em relação ao magistério, a proposta do governo Montoro contemplou um conjunto de medidas voltadas para a revalorização do professor. Segundo Palma Filho (2004, p. 6), a principal medida visou:

[...] equilibrar dentro da carga horária de trabalho as horas dedicadas às aulas propriamente ditas, com o número de horas atividade, destinada à preparação de aulas, correção de trabalhos, coordenação interdisciplinar e pedagógica, bem como reciclagem e aperfeiçoamento do corpo docente.

Apesar das expectativas criadas no sentido de criar condições para o aperfeiçoamento dos professores, os problemas estruturais da educação pública de mantinham. Assim, as ações de formação, como as estabelecidas pelo Decreto, se perdiam em meio aos alarmantes indicadores que mostravam os graves problemas da educação paulista. 
Posteriormente, no governo de Orestes Quércia (1987-1990) ocorreu, em 1988, a implantação da Jornada Única para os alunos e professores do ciclo básico paulista, cujo objetivo era ampliar e garantir a formação individual e coletiva dos docentes, visando o aperfeiçoamento profissional. Portanto, mais uma vez, medidas esporádicas e emergenciais, que pouco contribuíram para melhorias nas condições de trabalho e na formação continuada dos professores da rede estadual de ensino de São Paulo, eram anunciadas.

Em 1995, e já no contexto do primeiro governo de Mário Covas (1995-1998), ocorre, por meio do Decreto n. 40.473 de 21 de novembro de 1995, a reorganização das escolas da rede pública paulista. Implantada no contexto de uma ampla reforma da educação, que alterou de maneira significativa a organização das escolas da rede, o Programa de reorganização das escolas da rede pública estadual definiu que a distribuição das classes, a partir de 1996, passaria a ser em escolas de Ciclo Básico à $4^{\mathrm{a}}$ série; $5^{\mathrm{a}}$ à $8^{\mathrm{a}}$ série; $5^{\mathrm{a}}$ à $8^{\mathrm{a}}$ série; e $2^{\mathrm{o}}$ grau. As justificativas apresentadas mencionavam que a concentração de alunos em idades tão distintas, em um mesmo espaço, não contribuía para um bom ambiente educacional, e era um fator que poderia gerar situações de violência entre os alunos. Alegavam, também, que por ser uma rede de ensino muito grande, o controle da matrícula era dificultado, gerando situações em que não se sabia ao certo as demandas de professores, o que implicava na contratação de professores e construção de escolas sem necessidade. Uma outra razão alegada para a reforma era de que ela proporcionaria uma maior racionalização dos recursos e investimentos. (GOULART; PINTO \& CAMARGO, 2017).

Os problemas que essa reforma gerou para os professores foram imensos, pois a partir dela surgiu a necessidade de diversos professores trocarem de unidades escolares, com a consequente reclassificação para fins de atribuição de aulas. Além disso, a tão propalada preocupação em organizar as escolas de acordo com a faixa etária dos alunos, logo foi substituída pela política de municipalização do ensino fundamental. É inegável que a ação da SEE/SP, ao reorganizar as escolas da rede, facilitou o processo de municipalização.

Foi no contexto dessa reorganização, especificamente no processo de sua implantação, em 1996, que a SEE/SP criou o cargo de Professor Coordenador Pedagógico. No entanto, rompendo com os avanços democráticos alcançados na década anterior, o processo de criação da função de coordenação pedagógica ocorreu sem nenhuma consulta aos professores, que foram apenas comunicados sobre as alterações que estavam em curso nas escolas.

Como estratégia para disseminar os princípios da reforma, a SSE/SP definiu que os Novos Coordenadores deveriam utilizar a recém criada Hora de Trabalho Pedagógico Coletivo (HTPC). Assim, em seu princípio, tanto a função do coordenador de ensino, quanto a HTPC, pouco contribuíram para a formação continuada dos professores ou para o processo de democratização da 
gestão escolar. Pelo contrário, passaram a ser um espaço para a disseminação da narrativa reformista, para sua inserção no cotidiano dos professores. Esse processo, necessariamente, não significou a adesão completa, ou até mesmo a aceitação das ideias difundidas pelo discurso oficial, pois construção, pelos professores, das referências que orientam seu trabalho é mediado pelos documentos e orientações oficiais, mas não somente por elas. Outros processos definem a compreensão que o professor tem de seu trabalho, especificamente sua trajetória de vida, sua formação, a compreensão que possui da educação e de seu trabalho

Posteriormente, em 2008, a Lei n 11.738 de 16/07/2008 definiu o piso nacional docente, bem como estabeleceu que o limite máximo da carga horária docente em sala de aula seria de $2 / 3$ (dois terços) da carga horária total. O objetivo foi criar melhores condições de trabalho para os docentes, especificamente pela definição de um piso nacional para os salários. Trata-se, portanto, de uma medida importante, pois possibilita que as redes de ensino criem melhores condições para os processos de formação continuada dos professores.

Nas escolas da Rede Estadual de Ensino de São Paulo, o processo de adequação à legislação federal se deu por meio da Resolução no8, de 19/01/2012, que definiu a jornada de trabalho docente, estabelecendo que um professor com jornada de 32 horas de trabalho com alunos, teria 3 horas de Aula de Trabalho Pedagógico Coletivo e 13 horas em locais de livre escolha.

Em 2014, a SEE/SP, via Coordenadoria de gestão e Educação Básica (CGEB), publicou documento Aula de Trabalho Pedagógico Coletivo - ATPC em destaque, definindo as regras para sua organização. Na Resolução, é estabelecido que as ATPC devem

\footnotetext{
[...] ser utilizadas para reuniões e outras atividades pedagógicas e de estudo, de caráter coletivo, organizadas pelo estabelecimento de ensino, bem como para atendimento a pais de alunos. Convém considerar a importância de atualização dos aportes legais, incentivada pelos gestores, de modo a garantir o conhecimento das alterações normativas. É de suma relevância promover a gestão participativa, para que todas as tomadas de decisão, realizadas neste espaço, sejam concretizadas e produzam resultados positivos, para a melhoria do ensino. Convém ressaltar, que o parágrafo único, do artigo 13 da Lei Complementar No 836 de 1997, dispõe, também, sobre as Horas de Trabalho Pedagógico em Local de Livre Escolha - HTPL, pelo docente, as quais se destinam à preparação de aulas e à avaliação de trabalhos dos alunos. Espaço que poderá ser aproveitado para melhor organização do trabalho realizado, como por exemplo, para planejamento de práticas interdisciplinares e contextualizadas. (SEE/SP, 2014, p. 10)
}

Recentemente, em 2020, já no contexto da pandeia da COVID-19, a Secretaria da Educação estabeleceu as atividades a serem realizadas pelos professores durante o período de fechamento das escolas, incluindo a ATPC de forma remota. Além disso, a Secretaria definiu que as ATPC devem ser realizadas semanalmente, com o objetivo de planejar e conduzir as atividades pedagógicas. 


\section{Apontamentos, contribuições e críticas à ATPC no Estado de São Paulo}

Estamos vivendo em um contexto de profundas transformações, que exige constantemente que o professor seja capaz de compreender a realidade educacional de forma ampla. Em um cenário como este, o coordenador pedagógico tem sido instado a desempenhar o papel de articulador, estimulando o trabalho grupal, condição essencial para melhorar a práxis pedagógica e definir os objetivos comuns da escola, cuidando para que esse compromisso seja assumido na elaboração do PPP e possa ser concretizado. (SANTOS, 2000)

Nesse contexto, a formação continuada do professor é uma necessidade constante, pois é um espaço propício para a organização do trabalho pedagógico, e para os momentos coletivos de compreensão e crítica. Portanto, a função do coordenador pedagógico nesse cenário é desafiante, pois cabe a ele criar as condições para que os professores possam assimilar a formação na ATPC, o que implica na necessidade de dispor de textos, vídeos e estudos de caso que propiciem a reflexão sobre a prática pedagógica.

No espaço de ATPC, as reuniões pedagógicas são consideradas como palcos de negociacõoes, no qual a estrutura educacional converte-se em palco de encenações, que acaba cumprindo, muitas vezes, um papel meramente formal. É necessário, então, buscar a forma mais adequada de se conciliar a estrutura educacional como lócus de formação, com projetos que estimulem e promovam o desenvolvimento profissional do professor.

Considerando sua história, a ATPC foi criada com a finalidade de abordar aspectos relacionados com a realidade educacional e a formação dos professores. No atual contexto, esse caráter foi perdido, tendo assumido uma natureza meramente burocrática (MENDES, 2008). É importante destacar que essa descaracterização da ATPC é agravada quando as atividades propostas não estão relacionadas às reais necessidades dos professores, gerando um descompasso entre a formação continuada e as reais necessidades formativas dos educadores.

Assim, as reuniões de ATPC devem ser utilizadas com o objetivo de aprimorar os relacionamentos interpessoais de todos os envolvidos nesse processo e, com isso, promover vínculos grupais: professor-professor, professores e coordenador. Dessa forma, esse momento é fundamental, devendo ser planejado de forma minuciosa e com bastante dedicação pela equipe pedagógica e proporcionar aos docentes a assistência teórica necessária e, consequentemente, suporte pedagógico, para que eles se desenvolvam como profissionais competentes nesse novo cenário.

Nas reuniões de ATPC, é de responsabilidade do coordenador definir a pauta, mas tendo o cuidado e a atenção com as questões que são mais próximas dos professores e de seu cotidiano. O coordenador precisa de tempo para expor o planejamento adequado nessa reunião, em um ambiente descontraído, agradável e harmonioso, para que os participantes possam trocar suas visões 
sobre os temas em debate. Dessa maneira, o ambiente é um elemento muito importante. Se a reunião não for um ambiente descontraído e confortável, os participantes não somente terão dificuldades de se concentrar e fazer registros, como a reunião se tornará uma atividade meramente burocrática. Perde-se, assim, o sentido original da ATPC, que seria de um espaço de motivação e estímulo para o desenvolvimento das atividades coletivas, que promova o diálogo e defina o projeto da escola, considerando concepções e necessidades de todos os docentes envolvidos na conjuntura.

Por fim, o docente coordenador, ou formador do corpo docente, deve buscar envolver sua equipe educacional no processo de decisão, para que contribuam para qualificar os processos de ensino-aprendizagem. Além disso, deve ouvir os professores e considerar os temas mais relevantes, o que implica em manter um diálogo constante com eles. Deve, também, buscar trocar informações, estimulando o grupo, compartilhando seu diagnóstico prévio das reais demandas formativas do corpo docente, a partir das necessidades da escola. Um outro ponto importante é ter uma boa pauta, pois isso revela a importância e o sentido desses espaços formativos, ao fornecer aos docentes todo o planejamento e responsabilidade do planejamento feito de maneira minuciosa.

\section{Considerações finais}

Entendemos que o trabalho coletivo da ATPC é fundamental, uma vez que é parte de um contexto que cria condições para o debate sobre os problemas da escola. Inúmeras discussões e pesquisas, centradas em questões como qualidade e democratização da escolarização, apontam que novas perspectivas de organização das instituições escolares surgem quando os professores são ouvidos, quando debatem seus problemas e quando procuram soluções para esses problemas de forma coletiva. A ATPC é importante para transformar a gestão democrático-participativa, fundada no planejamento coletivo das atividades, na democratização da tomada de decisão nas escolas, no fortalecimento das relações humanas produtivas em prol de objetivos comuns em processo constante, dentro da cultura escolar.

Nesse contexto, a atividade da ATPC deve procurar ser um espaço onde haja motivação e estímulo para o desenvolvimento das atividades coletivas, promovendo o diálogo entre o que pensam os professores individualmente, com as concepções e necessidades de todos os docentes envolvidos, e o projeto político pedagógico da escola.

Entendemos, também, que a garantia a todos os professores, dentro da jornada docente, de momentos efetivos de formação, como a ATPC, pode viabilizar a formação continuada docente, e abrir possibilidades de pensar o cotidiano escolar e encontrar meios e soluções de seus problemas. 
Ao observamos a trajetória da ATPC na rede estadual de ensino de São Paulo, as perspectivas não são as melhores. A criação da ATPC foi uma demanda histórica dos professores e de suas instituições sindicais, e a forma como ela foi instituída pela SEE/SP nem sempre atendeu as expectativas dos professores. A ATPC sozinha pouco ou nada afeta o contexto geral da formação continuada do professor.

Além disso, as condições de trabalho oferecidas e a forma como a carreira docente está definida não são elementos que ajudam no processo. A ATPC precisa estar articulada ao contexto geral da carreira docente, o que implica discutir a fragmentação da jornada, da carreira e a classificação dos professores em diferentes categorias. Da mesma forma, é preciso criar condições para que o professor possa exercer sua atividade em uma única escola, por um período razoável, sem ficar se deslocando constantemente.

Outra questão fundamental é a própria definição da função de coordenador. Se o coordenador é fundamental para a boa consecução dos objetivos da ATPC, é fundamental que ele seja preparado para isso. O coordenador não pode ser um professor escolhido a cada período, por razões que nem sempre são pedagógicas. É preciso que haja o cargo de coordenador na estrutura da rede; que este seja definido com base em requisitos inerentes ao trabalho de coordenação; que haja concurso público; e que seja selecionado o profissional mais bem capacitado. Afinal, uma boa política pública com resultados significativos não se pauta em propostas pontuais e fragmentadas.

Considerando o que foi colocado, o longo processo de regulação da ATPC, que teve início nas primeiras ações da SEE/SP na década de 1980, e que se estende, inclusive, até o momento da pandemia de COVID-19, mostra, que embora a sanha de regulação tenha sido ampla, os resultados produzidos são limitados e com pouca aderência dos professores, uma vez que, em muitas situações, os horários de ATPC são mais espaços de lamentações do que de formação.

\section{Referências}

BRASIL. Conselho Nacional de Educação. Resolução CNE/CP n. 02/2015. Define as Diretrizes Curriculares Nacionais para a formação inicial em nível superior (cursos de licenciatura, cursos de formação pedagógica para graduados e cursos de segunda licenciatura) e para a formação continuada. Brasília, DF, 2019. Disponível em: http://pesquisa.in.gov.br/imprensa/jsp/visualiza/index.jsp?data $=02 / 07 / 2015 \& a m p ; j o r n a l=1 \& a m p ;$ pagina $=8 \&$ amp;totalArquivos $=72$. Acesso em 15 jul 2020.

BRASIL. Resolução CNE/CP nº 2, de 20 de dezembro de 2019. Define as Diretrizes Curriculares Nacionais para a Formação Inicial de Professores para a Educação Básica e institui a Base Nacional Comum para a Formação Inicial de Professores da Educação Básica (BNC-Formação). Brasília, DF, 2015. Disponível em: http://portal.mec.gov.br/docman/dezembro-2019-pdf/135951rcp002-19/file. Acesso em 17 jul 2020. 
GEPD - Grupo de Estudos das Práticas Docentes. HTPC como lugar de formação continuada dos professores. 2020. Disponível em https:// esquerdaonline.com.br/2020/04/24/htpc-como-lugar-deformacao-continuada-dos-professores/. Acesso em 21 jul 2020.

GOULART, D. C., PINTO, J. M. R., \& CAMARGO, R. B. de. (2017). Duas reorganizações (1995 e 2015): do esvaziamento da rede estadual paulista à ocupação das escolas. ETD-Educação Temática Digital, 19, 109-133. Disponível em: https://doi.org/10.20396/etd.v19i0.8647797. Acesso em 20 set 2020.

PALMA FILHO, João C. Reorganização do Ensino Fundamental na Rede Estadual de Ensino do Estado de São Paulo, Política e Ideologia: memória. In: PALMA FILHO, João C., TOSI, Pedro G. (Org.). Pedagogia Cidadã: Cadernos de Formação: Política e Economia da Educação. São Paulo: UNESP, Pró-reitoria de graduação, 2004.

SÃO PAULO (Estado). Coordenadoria de Estudos e Normas Pedagógicas. Portaria CENP $n^{\circ}$ 1/96 - L.C. n 836/97. São Paulo: SE, 1996.

SÃO PAULO (Estado). Secretaria da Educação. Resolução SE nº 08, de 2012. São Paulo: SE, 2012.

SÃO PAULO (Estado). Documento Orientador CGEB: Aula de Trabalho Pedagógico Coletivo (ATPC) em Destaque. São Paulo: SE, 2014.

SÃO PAULO (Estado). Resolução SE $n^{\circ} 08$, de 19 de janeiro de 2012. Dispõe sobre a carga horária dos docentes da rede estadual de ensino. São Paulo: SE, 2012.

SANTOS, D. S. Registro: Importante Ferramenta para o Aperfeiçoamento do Trabalho Pedagógico. In: Portal Educação, publicado em 30. out. 2012. Disponível em: https://www.portaleducacao.com.br/conteudo/artigos/educacao/registro-importante-ferramenta-para-o-aperfeicoamento-do-trabalho-pedagogico/20755. Acesso em 12 jan 2020. 